\title{
A prosa latina clássica e a acribia na comunicação
}

\author{
ARIOVALDO AUGUSTO PETERLINI \\ Faculdade de Filosofia, Letras e Ciências Humanas \\ Universidade de São Paulo
}

RESUMO: Os objetivos da comunicação: o pragmatismo moderno e o aniquilamento do pessoal sob a pressão do interesse econômico. How to get your point across in 30 seconds - or less. Que idéias podem caber em 30 segundos - ou menos? Com tantos e tão profundos estudos da linguagem em nosso tempo, por que vem decrescendo, entre nós, a habilidade de expor os próprios pensamentos? Teria sido mal interpretada a mensagem dos modernistas? Ou a preocupação dominante, nos meios universitários, com a língua falada, preocupação nascida já de motivos políticos, já do desprezo a que foi essa língua relegada por séculos, estaria desmerecendo nos mestres da língua culta e, inadvertidamente, fechando aos nossos jovens o acesso à cultura humana de séculos, que se acumula nas bibliotecas, quase sempre em língua culta? 0 trabalho constante sobre os textos latinos e gregos não é, por certo, o único caminho para alguém conseguir a propriedade, a precisão, a transparência na comunicação escrita, mas foi e continua sendo um dos meios mais adequados para isso. $O$ latim só chegou até nós fixado numa forma escrita, quase livre de subsídios externos de entendimento, e está vazado em nível culto, onde normalmente cada palavra tem sua importância. Ora, é a krísis, a escolha do termo e da construção exatos da língua de chegada, para traduzir com acribia o sentido preciso do latim - operação em extremo mais fácil entre as línguas vivas - que pode criar o hábito de uma visão analítica do que se escreve.

PALAVRAS-CHAVE: Acribia; comunicação; precisão; latim.

O império do prático-econômico, reduzindo a comunicação ao mínimo de palavras e ao máximo de persuasão, por qualquer meio, racional, emotivo, ilusório, é a marca mais que registrada de nossa época. O homem, animal racional?! O homem, a medida de todas as coisas?! O homem, centro do universo?! Não. O homem é um animal consumidor, comprador, gerador de riquezas... Se não é isso, não é "homem". E a comunicação entre os homens a outro alvo não mira, senão a esse, o econômico. Até o verbo vender adquiriu, entre nós, um novo sentido intransitivo: Um livro é importante, se vende muito; uma composição musical é divulgada, enquanto vende. Para aquilatar-se do valor de uma obra de arte, diz-se que foi vendida por milhares de dólares...

Assusta a quem acompanha, desde os gregos, o nascimento, a vida, a morte e a ressurreição da arte de falar e de escrever, ou seja, da velha-nova retórica de Aristóteles, de 
Cícero, retomada v.g. por Lausberg ou pelos modernos tratadistas como Perelman, assusta a proposta em extremo sedutora de uma retórica tão "econômica", em todos os sentidos, qual a que nos recomenda o pequeno livro de Milo Ogden Franc, editado em 1986 e já em nona edição entre nós: Como apresentar as suas idéias em 30 segundos - ou menos (How to get your point across in 30 seconds - or less). Um laconismo capaz de fazer inveja a qualquer espartano! A carreira de sucesso do autor, já como agente de artistas de Hollywood, já como encarregado de atualizar os métodos de comunicação entre gerentes e equipes de grandes empresas, mostra que o trabalho de Milo Franc caiu em graça ao pragmatismo norte-americano. E, receoso, vou-me imaginando a ler, em comunicação de 30 segundos - or less, as mensagens de Platão, de Aristóteles, de Cícero, de Kant, de Hegel, de Heidegger etc.! O que pode caber de importante em 30 segundos - ou menos? Milhões de dólares, sem dúvida! O apertar de um botão que detonará a bomba de hidrogênio! Mas as idéias que levaram à evolução e ao maravilhoso enriquecimento do espírito humano, no correr dos séculos, exigiram sempre um pouco mais de tempo, espaço, paciência e dedicação...

O registro lento desse progresso humano veio-se acumulando, por toda a nossa história, em volumes e volumes pelas bibliotecas das civilizações, nas mais diversas línguas, cujo domínio foi sempre fonte de conhecimentos e progresso. Quanto mais complexo o pensamento, tanto mais especializado e exigente o nível de linguagem e, é claro, tanto mais restrito o acesso a essa comunicação. Se manuais de primeiros socorros expõem uma medicina prática, em expressões mais rápidas e acessíveis, para mais fácil conhecimento do indispensável, ninguém espera que seu médico haja conseguido o diploma apenas com a instrução que se contém nesses manuais.

Falar e escrever, em nível apto a receber ou emitir mensagens de teor altamente abstrato, significa competência para decodificar ou construir sistemas de idéias capazes de transformar a vida e a história da humanidade. Reduzir o domínio das palavras é limitar o âmbito das idéias. Contentar-se com a linguagem cotidiana é fechar as portas das bibliotecas e negar a muitos o quanto foi entesourado em nível culto de linguagem, isto é, praticamente a maior parte do legado escrito pelos grandes mestres.

Nosso Drummond (1969, p. 67 e 76), em seus poemas "O lutador" e "Procura da poesia", nos adverte:

Lutar com palavras

é a luta mais vã.

Lutar com palavras

parece sem fruto

e nos pede:

Chega mais perto e contempla as palavras.

Cada uma

tem mil faces secretas sob a face neutra 
e te pergunta, sem interesse pela resposta, pobre ou terrível, que lhe deres:

Trouxeste a chave?

É evidente que o Poeta se refere aos valores conotativos da palavra, ao uso poético da linguagem, mas tenho para mim que, como bom vate, poeta-adivinho, passem-me a comparação, vate, poeta-profeta, Drummond diz bem mais do que pretende dizer, alcançando, intuitivamente, o plano denotativo, campo onde a luta com as palavras também não é fácil e a chave, não menos essencial.

Aristóteles, na cola de Platão, passa do mundo das idéias para os universais fixos, imutáveis e necessários, que formamos a partir da realidade das coisas, longe das idéias inatas ou da reminiscência, numa estreita conexão entre a ordem lógica e a ontológica. As coisas, materiais, são objeto, primeiro, do conhecimento sensível: se visíveis, se audíveis, se tangíveis etc., nossos sentidos formarão delas imagens visíveis, audíveis, tácteis etc. Mas, sem transcender o particular, essas imagens criadas pelos sentidos, à luz v.g. do sol, não são de si objeto adequado do conhecimento intelectivo; são um exército em debandada de imagens sensíveis, só potencialmente inteligíveis e cuja imagem inteligível será obra dum intelecto iluminador ativo, capaz de abstrair do sensível a imagem inteligível e apresentála a um intelecto passivo, receptáculo em potência das idéias, apto a pensar-se a si mesmo, onde o exército dos particulares se reorganiza na unidade dos universais (Aristóteles, Anal. Post. II, 19, 100 a 1-8. Met. I, 1, 980 b 26 - 982 a 3, apud Fraile,1965, p.441-442; e De anima, III, 4, 429 a - 430 a: 5, 430 a 15, apud Fraile,1965 p. 449-500).

Implorando, mais que perdão, piedade pela ousadia de termos reduzido a uma exposição de 30 segundos - or less a teoria do conhecimento de Aristóteles, cujos ossos, a esta altura, devem ter-se revirado, onde estiverem, esperamos, todavia, haver deixado claro o caráter de imanência do nosso conhecimento, que, não obstante se refira ao mundo exterior a nós, é por nós criado sobre imagens sensíveis e inteligíveis que fabricamos a partir das coisas.

Curioso como, por outros caminhos, o Poeta (Drummond, 1980, p.14-15) nos leva a refletir, com algum receio, sobre a realidade de um mundo que só chega ao nosso conhecimento, através dos nossos sentidos:

Estrela não pensada,

palavra rascunhada no papel

que nunca ninguém leu?

Existe, existe o mundo

apenas pelo olhar

que o cria e lhe confere

espacialidade?

Concretitude das coisas: falácia

de olho enganador, ouvido falso,

mão que brinca de pegar o não 
e pegando-o concede-lhe

a ilusão de forma

e ilusão maior, a de sentido?

Se nosso conhecimento indutivo precisa ser testado respeito à realidade do mundo exterior, para ser tido por verdadeiro, na busca de uma adequação, o quanto possível perfeita da inteligência às coisas, o que devemos pensar quanto às deduções? E isso no campo do denotativo. Mas, a que vêm aqui todas essas considerações?

Se a palavra, o uerbum, é o principal meio "convencionado" para comunicar a outra inteligência o nosso entendimento, máxime no que tange ao segundo e terceiro graus de abstração, pode imaginar-se com que dificuldades, com que obstáculos tenha de ver-se a braços a comunicação pela palavra, quando a elaboração do próprio conhecimento já é tão complexa. E a dificuldade crescerá, na medida em que for mais pessoal e original o pensamento, até alcançar o plano das emoções, os "estados indizíveis" da alma, cuja comunicação por meio dos valores simbólicos, mais que pelos lógicos e semânticos das palavras, foi o sonho dos simbolistas.

Não visamos aqui ao ceticismo, no que tange à possibilidade do conhecimento ou da comunicação, mas apenas a que fique patente quão difícil é "lutar com palavras", na tentativa de comunicar, mesmo em plano denotativo, idéias e pensamentos, que nascem de imagens sensíveis e inteligíveis por nós mesmos criadas e sobre cuja representação verbal, esperamos que o nosso ouvinte ou leitor possa recriar, ainda de forma imanente, imagens sensíveis e inteligíveis o quanto possível iguais às nossas. Quem pode garantir a ausência de miopia, de hipermetropia, de daltonismo etc. no mundo do conhecimento humano, máxime quando se trata da convenção das palavras?!

Tendo alcançado já a idade do horaciano

\section{.........querulus, laudator temporis acti} se puero... (Horácio, A.P. 173-4),

ou seja, do

$$
\begin{aligned}
& \text { (“...lamurioso, apologista do tempo passado, } \\
& \text { quando era jovem ...”), }
\end{aligned}
$$

podemos dar-nos o direito a alguma jeremiada - Incipit lamentatio Ieremiae prophetae. Mas haja tranqüilidade, que não iremos além do Aleph.

Com tantos e tão profundos estudos da linguagem, em nossa época, seria de esperar que a habilidade de exposição, já oral, já por escrito, dos nossos pensamentos viesse também se aperfeiçoando a passo igual. Estranhamente aconteceu o contrário, pelo menos entre nós, brasileiros: os mais antigos, de normal, se expressam melhor. Influxo dos modernistas? Por certo não, que todos os nossos grandes do Modernismo conheciam a preceito as normas cultas da comunicação e as violentavam de caso pensado. Ou será que pela valorização 
justa da língua do povo, da língua falada, por tanto tempo banida, a língua culta teria esquecido no interesse dos novos?!

Os que orientamos em pós-graduação ou examinamos dissertações e teses, temos deparado, não raro, mesmo em pessoas de apreciável lastro cultural, dificuldades inúmeras na escolha do mais adequado à expressão escrita de suas idéias. Se dominam de plano o vocabulário, a morfologia e a sintaxe, o que não é comum, como penam, quando enfrentam com a disposição dos assuntos, a elaboração clara dos argumentos e, principalmente, a precisão dos termos, orações e períodos que sejam capazes de expor com acribia o que se pretende comunicar. Isso, para não falar dos que se aventuram pela "selva selvaggia ed aspra" de certas nomenclaturas e cujos trabalhos deveriam trazer por epígrafe o dantesco "Lasciate ogni speranza, voi ch'entrate..." Se, como latinista, somos suspeito no assunto, tomamoss a liberdade de trazer aqui o testemunho de um grande professor da F.F.L.C.H. da U.S.P., hoje aposentado, sociólogo e crítico literário cujo nome não nos achamos no direito de declinar, autor de obras que, sobre serem profundas, são por extremo transparentes e acessíveis, o que lhe tem merecido a admiração e o respeito incondicionais do meio intelectual brasileiro. Declarou-nos ele, de uma feita, em conversa ocasional, a dificuldade que por vezes sentia para entender os trabalhos de certos orientandos, pelo hieroglífico da nomenclatura ou das expressões e, coisa de intelectual humilde e honesto, seu receio em prejudicá-los na avaliação.

A razão principal dessa deficiência, todos sabemos, enraíza no ensino de primeiro e segundo graus, de uma parte, e, de outra, naquele velho desamor a que se referia, faz já alguns séculos, o poeta Antônio Ferreira (1961, p. 97):

Floresça, fale, cante, ouça-se e viva a portuguesa língua, e já onde for, senhora vá de si, soberba e altiva.

Se té qui esteve baixa e sem louvor, culpa é dos que a mal exercitaram, esquecimento nosso e desamor.

Que o problema tem a ver com o ensino das primeiras letras é o que já Cícero afirmava no De oratore, há um bom tempo atrás:

Neque enim conamur docere eum dicere qui loqui nesciat, neque sperare, qui latine non possit, hunc ornate esse dicturum, neque uero, qui non dicat quod intellegamus, hunc posse quod admiremur dicere. Linquamus igitur haec, quae cognitionem habent facilem, usum necessarium. Nam alterum traditur litteris doctrinaque puerili, alterum adhibetur ob eam causam, ut intellegatur quid quisque dicat, quod uidemus ita esse necessarium, ut tamen eo minus nihil esse possit (Cícero, Orat. III, X, 37-38).

("Com efeito, não pomos empenho em ensinar a falar em público a quem não sabe se exprimir, nem pretendemos esperar que fale com elegância 
quem não consegue falar corretamente, nem que aquele que não diz coisa que consigamos entender, possa dizer algo que nos cause admiração. Deixemos, portanto, essas qualidades, que são fáceis de adquirir, e de uso imprescindível. Uma (a vernaculidade) nos é transmitida pela primeiras letras e pela instrução da puerícia; a segunda (a clareza) é empregada para que se entenda o que alguém quer dizer, o que consideramos tão necessário, que é o mínimo que se pode exigir").

A correção, a vernaculidade, a clareza no escrever, de acordo com um padrão culto da língua, no momento histórico em que se vive, é a condição sine qua non com que alguém deve sair para a vida ou entrar para uma Faculdade. O estilo, o ornamento, a linguagem literária, a isso podemos nos abalançar com nossos próprios passos, mas, no tocante ao básico da língua, os bons mestres são imprescindíveis ao jovem aprendiz. Se professores competentes houver e não houver, nos discípulos, aquele velho desamor à portuguesa língua, de que nos fala o Poeta, por certo os nossos jovens, principalmente os que se propõem a ter por ofício o lidar com palavras, dominarão a arte do escrever correto e claro.

A fábula do cão que, nadando em um rio, deixa cair o pedaço de carne que traz na boca, para gananciosamente arrebatar à sua própria imagem refletida nas águas um pedaço de carne que julga maior, satiriza a avidez humana, mas parece-nos que vem a calhar também para o velho hábito dos homens de ter como integralmente verdadeiro quanto seja novo e belo e de abandonar, por ultrapassado, quanto o espírito humano amealhou em séculos.

Chesterton escreveu algures que a história do espírito humano lembra, por sua tendência aos extremos, um bêbedo a cavalo: dificilmente se mantém ereto na sela - ora pende para um lado, ora, para outro. Acreditamos que foi num desses extremos que a retórica, de arte de persuadir, algo intrínseco às relações humanas, transformou-se num cesto de flores, fim em si mesma e, como as flores, feneceu. Mas, como o que é essencial à realização do homem jamais perece de todo, a arte de persuadir, à feição da Fênix, ressurgiu das próprias cinzas, sobre as quais já tinham sido cantados tantos réquiens. La réthorique est morte, vive la rhétorique!

O sistema de educação de um povo não se forja nunca de improviso; compõe-se de séculos entesourados nos costumes, nas tradições orais, no silêncio fecundo das bibliotecas. É sobre tudo isso que a ânsia humana de progredir rola suas oceânicas e tempestuosas revoluções de renovação, que, ao serenarem, porque toda violência tem dias contados, deixam sempre algo novo e bom com que se acrescente o acervo do progresso já conquistado.

Há não muito tempo, nossos conhecimentos sobre linguagem e literatura eram bem tradicionais, vinham de longa tradição retórica e, à sua sombra, o mínimo que aprendíamos era a escrever e a falar dentro de uma relativa uniformidade que permitia entender e ser entendido. Aos artistas da palavra se deixava o direito de exorbitar. Hoje, com a explosão das teorias, assim na área linguística como na literária, já pelo labiríntico da nomenclatura, já pelo sutil de algumas propostas, o clã dos entendidos se elitizou e a preocupação com o usual indispensável tornou-se coisa de somenos.

De certo, ainda hoje, sem desconsiderar os inúmeros métodos que têm sido propostos, para falar e escrever por um padrão que faculte razoável entendimento da mensagem, não há como fugir à leitura dos bons autores antigos e modernos, ao empenho em aprender 
as normas gramaticais vigentes, assim como as regências verbais e nominais bem aceitas pela língua e, principalmente, cumpre escrever, escrever, escrever com cuidado e carinho, buscando sempre expressar, de forma "correta", transparente e não desagradável, o que se pretende dizer.

Chegamos, agora, ao fulcro desta exposição.

O trabalho constante e aturado sobre os textos latinos e gregos não é, por sem dúvida, o único caminho para alguém conseguir a propriedade, a precisão e a transparência na comunicação escrita, mas foi e continua a ser um dos meios excelentes para isso.

Umberto Eco, em pequeno trabalho, a que tivemos acesso apenas em tradução francesa de 1986, "La ligne et le labyrinthe: les structures de la pensée latine", partindo de dois versos de uma sátira de Horácio, faz algumas considerações que têm muito com o objetivo a que miramos aqui:

est modus in rebus: sunt certi denique fines

quos ultra citraque nequit consistere rectum.

(Horácio, Sat. I, I, 106-7)

("Existe em toda coisa uma medida:

há limites, em suma, bem marcados, para além, para aquém dos quais não pode encontrar-se jamais a retidão").

Fines, limites, fronteiras. É o termo de onde parte Umberto Eco, para uma análise do modus cogitandi latino, que acabou por marcar fundamente o modo de pensar da cultura ocidental.

Lembra-nos ele que a linearidade superficial da parataxe primitiva, v.g., das Leis das XII Tábuas, não impunha ainda qualquer linearidade lógica. Parece que foram as exigências jurídicas que, de modo autóctone, sob a necessidade de precisar limites e direitos, levaram os romanos a preocupar-se com os mecanismos da lógica, que acabaram por aperfeiçoar no contato com os gregos. Daí provém, sem dúvida, a lógica interna da sintaxe latina, que estrutura a frase, o período, o texto, numa coesão que, a nosso ver, pode fazer inveja à do inglês de Halliday.

"Nada", diz Umberto Eco, "é mais regular, ordenado, codificado que o modelo hipotático da consecutio temporum. Ele impede o pensamento de reconhecer os fatos incomuns, de alinhá-los e de vê-los, antes de ter encontrado uma ordem que os ligue. $\mathrm{O}$ texto latino clássico relacionou a ordem da linguagem, supondo sempre um nó entre os modi significandi, cogitandi, essendi".

Eco (1986, p.27-57) acredita que

o modo de pensar latino não pode dar conta da realidade inteira, em todas as suas contradições. E o pensamento moderno aprendeu a não 
temer a contradição. Mas, sem a assistência do pensamento latino, a realidade se arriscaria a transformar-se numa dança de átomos sem destino... Mesmo para falar de um universo sem limites e sem leis, é preciso, de uma maneira ou de outra, fixar um universo de discurso, e colocar, portanto, fronteiras, sejam elas embora mais lábeis e provisórias do que as com que sonharam os poetas da Pax Romana.

Essas considerações de Umberto Eco, nós as aduzimos, visando ao tema deste trabalho, a ajuda que o trato com a prosa latina clássica pode patrocinar à acribia, à precisão e à conseqüente clareza de nossa comunicação escrita, predicados da boa redação contra os quais vêm-se multiplicando os pecados da nova geração brasileira, naquele velho e impatriótico desamor à própria língua.

Se conhecer o latim é condição sine qua non para saber a fundo a língua portuguesa, não o é para escrever bem o português. Conhecemos quem escreva com precisão, clareza, correção e transparência a nossa língua, sem ser latinista. O que entendemos propor aqui é o quanto, nessa arte de transmitir pensamentos, por escrito, com acribia e clareza, podem ajudar as traduções bem elaboradas dos textos latinos clássicos em prosa.

Se uma língua houve que fixou, estruturou, justificou com múltiplos nexos transfrásticos as sequiências de um sistema lógico de comunicação escrita, foi o latim. Não há termo, não há frase, não há período que não tenha sua forma e função logicamente justificáveis num texto.

Quando falamos, as palavras se acompanham sempre dos chamados subsídios naturais, como a voz, os gestos, o ambiente, os conhecimentos que valem por base aperceptiva etc... Mas a língua escrita já por isso vai-se libertando desses subsídios na medida em que se afasta no tempo, até alcançar um estado quase puro, quando persiste apenas em sua fixação escrita, como sucede com os textos latinos e gregos, por exemplo, onde, por vezes, não temos mais que nomes, onde as coisas permanecem apenas pelos nomes, como a rosa antiga do Romance de Umberto Eco: "Stat rosa pristina nomine, nomina nuda tenemus" (Eco, 1987, p. 503). Entendemos, a partir disso, o motivo por que Pier Vicenzo Cova considera a didática da leitura do latim como a didática da leitura por excelência (Cova, 1982, p. 47-8).

A tradução de uma língua moderna ocidental para outra ocidental, por diversas que sejam as estruturas sintáticas, mantém quase sempre a natureza gramatical das palavras, geralmente o torneio das frases, o valor semântico, na maioria das vezes, bem determinado pelo vocábulo em ambas as línguas. Mas, quando se trata de traduzir um texto latino antigo para o nosso hic et nunc, cumpre atualizar sua semântica potencial com uma semântica atual, sem o auxílio dos subsídios contemporâneos do texto, o que não sucede com os textos modernos, máxime após o boom dos meios de comunicação, que hoje levam os homens a pensar as mesmas coisas e da mesma forma. Se a tradução mecânica chegar, um dia, à perfeição, gostaríamos de estar ainda vivo, para ver um computador escolher, dentro da elasticidade da polissemia dos vocábulos latinos, o sentido exato para a palavra da língua de chegada.

Aí reside o imenso benefício da tradução do texto latino clássico para um texto atual. O compromisso de manter a nitidez, a acribia do texto de partida, no texto de chegada, vai 
exigir de quem traduz a identificação do sentido tencionado pelo autor latino para cada vocábulo, para cada frase e para isso contará apenas com o texto escrito, no máximo, com o contexto. Nenhum outro subsídio haverá, na maioria dos casos. Ora, esse trabalho, primeiro, de precisar o sentido do texto de origem e, depois, de reapresentá-lo em língua hodierna, com igual nitidez, acaba por desenvolver no tradutor o hábito do estudo analítico do texto antigo e do estudo analítico e prático com respeito à construção do moderno. Desse exercício nascem os hábitos de análise, de lógica, de precisão ou acribia, assim no exame do texto latino antigo como na reconstrução desse texto em língua atual.

A proximidade e convivência das línguas atuais permite que, embora desaconselhável, do molde em que se vazou uma frase, por exemplo, francesa, se possa transferi-la para um molde inglês, alemão, italiano, português etc., sem que o tradutor se dê conta do seu inteiro conteúdo. No caso da tradução de um texto latino antigo para língua moderna, isso é impossível, visto que, nesse caso, a operação há mister o entendimento perfeito do texto de partida, obrigando o tradutor a avaliar cada vocábulo, a precisar-lhe o valor a todas as luzes, a buscar-lhe o equivalente atual, a dominar o sentido inteiro do texto: é trabalho da alçada não de mero tradutor, mas quase de um pensador (Breal, 1981, p. 42 -3 e 75).

Mas além desse exercício inteligente de transporte de língua para língua, que, evidentemente, jamais esteve entre os objetivos que moveram a elaboração dos textos latinos clássicos, não é reduzido o número de textos em que se contêm lições e normas para escrever bem, dentro do ideal de equilíbrio e lógica latinos do modus e dos fines horacianos, sempre na busca do elevado, mas transparente ao leitor a que se destina, o que lembra e bem o conselho de Vieira (1963, p.110), no "Sermão da Sexagésima":

Aprendamos do céu o estilo da disposição e também o das palavras. Como hão de ser as palavras? Como as estrelas: as estrelas são muito distintas, e muito claras, e altíssimas. O estilo pode ser muito claro e muito alto; tão claro, que o entendam os que não sabem, e tão alto, que tenham muito que entender nele os que sabem.

Para que se possa fazer alguma idéia do teor desses textos latinos conselheiros do bem escrever, vai aqui uma pequena amostra de Cícero, que é quem mais disso se ocupa, antes de Quintiliano:

Neque uero in illo altero diutius commoremur, ut disputemus quibus rebus assequi possimus ut quae dicamus intellegantur, latine scilicet dicendo, uerbis usitatis ac proprie demonstrantibus ea quae significari ac declarari uolemus, [sine ambiguo uerbo aut sermone], non nimis longa continuatione uerborum, non ualde productis iis quae similitudinis causa ex aliis rebus transferuntur, non discerptis sententiis, non praeposteris temporibus, non confusis personis, non perturbato ordine. Quid multa? Tam facilis est tota res, ut mihi permirum saepe uideatur, cum difficilius intellegatur quid patronus uelit dicere, quam si ipse ille, qui patronum adhibet, de re sua diceret (Cícero, Orat. III, XIII, 48-9). 
("Não vamos insistir também, por tempo mais longo, sobre o outro ponto, isto é, de que meios possamos valer-nos, para que se entendam as coisas que dizemos, ou seja, do falar vernaculamente, com palavras correntes, capazes de expressar bem o que pretendemos que seja significado e declarado [sem vocábulo ou discurso ambíguo]; dos períodos não longos em demasia; do uso moderado das expressões que, em razão da semelhança, são metaforicamente transferidas de outras coisas; das frases não descosidas; da falta de correlação dos tempos; do não confundir as pessoas; do respeito à ordem. Por que dizer mais? Tudo isso é tão fácil, que, frequientemente, me parece por extremo espantoso o fato de que há mais dificuldade em atinar com o que o advogado de defesa quer dizer, do que haveria, se aquele, que se vale do advogado, expusesse ele mesmo a sua causa”).

Se Cícero vivesse hoje, não creio que escreveria diversamente. Só não concordamos com o seu "tam facilis est tota res" (tudo isso é tão fácil), porquanto, mesmo na linguagem denotativa continua valendo aquilo de Drummond:

\section{Lutar com palavras parece sem fruto.}

Também para Marouzeau a tradução deve ser e manter-se uma luta. Mais que um exercício de latim e que um exercício de língua materna, a tradução pode ser um frutuoso exercício de método e um ato de probidade intelectual (Marouzeau, 1970, p. 150).

$\mathrm{O}$ verbo escolhido nada tem de fácil: lutar. Luta para alcançar as cinco qualidades que Cícero propõe como faróis do texto bem redigido:

Communia autem simplicium coniunctorumque sunt haec quinque quasi lumina, dilucidum, breue, probabile, illustre, suaue (Cícero. Part. orat. V, 19).

("São comuns às [palavras] empregadas isoladamente e às unidas a outras estas cinco qualidades, como que luminárias [da elocução]: a clareza, a concisão, a conveniência, o brilho, o deleite").

Os textos que nos ficaram dos séculos passados são os campos de batalha onde essa luta com palavras foi vencida, pois os pensamentos, as alegrias, as tristezas, as emoções que a humanidade viveu, ao longo de sua história, só permanecem pela palavra, não temos mais que palavras: stat rosa pristina nomine, nomina nuda tenemus.

\section{Referências bibliográficas}

BREAL, Michel. De l'enseignement des langues anciennes. Paris: Librairie Hachette et Cie, 1891. 
CICÉRON. De l'orateur. Paris: "Les Belles Lettres", 1956.

. Divisions de l'art oratoire. Topiques. Paris, "Les Belles Lettres", 1960.

COVA, Pier Vicenzo. Latino e didattica della continuitá. Brescia: Editrice La Scuola, 1982.

DRUMMOND de Andrade, Carlos. Reunião. Rio de Janeiro: Liv. José Olympio, 1969.

. A paixão medida, $2^{2}$ ed. Rio de Janeiro: Liv. José Olympio, 1980.

ECO, Umberto. "La ligne et le labyrinthe: les structures de la pensée latine". In: DUBY,George. Civilization Latine. Paris: Éditions Olivier Orban, 1986. Il nome della rosa, 22" ed. Milano, Ed. Bompiani, 1987.

FERREIRA, Antônio. Poemas Lusitanos - Seleção de F. Costa Marques. Porto: Ed. Atlântida, 1961.

FRAILE, Guillermo. Historia della Filosofia. Vol.I. BAC - Madrid: L'Editorial Catolica S.A., 1965.

FRANC, Milo Ogden. Como apresentar as suas idéias em 30 segundos - ou menos. $9^{\mathrm{a}}$ ed. (How to get your point across in 30 seconds - or less) - Rio de Janeiro: Editora Record, 1996.

MAROUZEAU, J. Introduction au latin. Paris: "Les Belles Lettres", 1970.

VIEIRA, Pe. Antônio. Sermões. Rio de Janeiro: Livr. Agir Editora, 1963.

PETERLINI, Ariovaldo Augusto. Classical Latin prose and accuracy in communication. Classica, São Paulo, 13/14, p. 331-341, 2000/2001.

ABSTRACT: The objectives of communication: modern pragmatism and the annihilation of personal interests under the pressure of economic ones. How to get your point across in 30 seconds - or less. Which ideas could fit in 30 seconds - or less? With so many deep studies of language in our present time, why has the ability of expressing our own thoughts been decreasing among us? Could it be that the message of the modernists has been misunderstood? Would the main interest in the spoken language in the academic world (an interest born either from political reasons or from the disdain to which spoken language had been relegated for centuries) be diminishing among the masters of the cultured language and, inadvertently, preventing our young men from accessing the centennial human knowledge accumulated in libraries, nearly always written in cultured language? The permanent work on Greek and Latin texts is not, certainly, the only way for someone to achieve the propriety, the precision, the transparency of written communication, but it was, and still is, one of the most adequate means for this. Latin came to us fixed only in its written form, almost free from external aid, and is presented in the cultured variety, where usually each word has its importance. To translate with accuracy the precise meaning of the Latin text it is the "krisis" - the choice of the term and of the precise construction of the target language, - an operation much easier than that between living languages - which may create the habit of an analytical view of what is being written.

KEYWORDS: Accuracy; communication; precision; Latin. 